\title{
011001100110111101110010011001010111001101110100 [forest]
}

\author{
Danielle Svehla Christianson ${ }^{\text {a }}$ \\ Keywords: representation, visualization, virtual reality, science, ecology, forests \\ https://doi.org/10.1525/001c.13389
}

\begin{abstract}
Visual and numerical abstraction is an everyday affair in ecological research. Technologies capable of collecting and analyzing increasingly finer resolution observations of the environment are becoming common. The resulting new, often visual and digital, forms of representation blur the abstraction and the abstracted. I examine the role of visualization in science practice using a case study of microclimate effects on tree seedlings in a forest with 3D laser scanning and virtual reality technologies. I describe advantages such as continuity across multiple spatial scales, lively interactions, and new perspectives. In addition, I explore potential risks including a false sense of omnipotent control, incomplete representations, singular inscription, and limits to participation. I aim to develop a framework for ecologists to harness the opportunities of new visual technologies in a responsible practice that minimizes their risks.
\end{abstract}

Between 2008 and 2014, I conducted an ecological study of the effects of microclimate on tree seedlings in the red fir forest montane ecosystem of California's Sierra Nevada in Sequoia National Park. What follows is a scientist's reflection on the increasingly computer- and data-driven processes used to collect, visualize, and interpret traditional field-based observations. During this study, I employed typical scientific procedure utilizing a series of common scientific representations: charts, diagrams, photographs, graphs. The fundamental process: collect quantifiable bits and reconfigure them into a representation of the system. After scanning my 1-hectare study site with a terrestrial laser scanner and viewing the resulting point cloud data on my computer screen (figure 1), it became blatantly obvious that I had turned this complex collection of organisms and the physical environment into discretized 0 s and 1 s.

Scientists have long used representations to great effect. In particular, visual representations hold an elevated status in communicating knowledge (Latour 1990; Baird et al. 1993; Miller and Burton 1994). Many science and technology studies (STS) scholars have described this core methodology, highlighting its benefits and also its epistemological risks, both often stemming from technological advances (Latour 1990; Haraway 1991b; Vertesi 2014). In this era of big data and associated digital technologies, my use of such a technology, terrestrial laser scanning (also known as LiDAR), with its 2D and 3D visualizations of point cloud data, offers an opportunity to explore how new practices of visual representation affect ecological study.

\footnotetext{
a Danielle Svehla Christianson is a computer science engineer in the Data Science and Technology Department at Lawrence Berkeley National Laboratory. As a member of the Usable Software Systems Group, Christianson combines her background in mechanical engineering, ecological research of microclimate in forests, and study of digital representations of natural systems to build usable data management tools for earth science research. Christianson is an alumna of the Energy and Resources Group and the Berkeley Center for New Media at the University of California, Berkeley.
} 


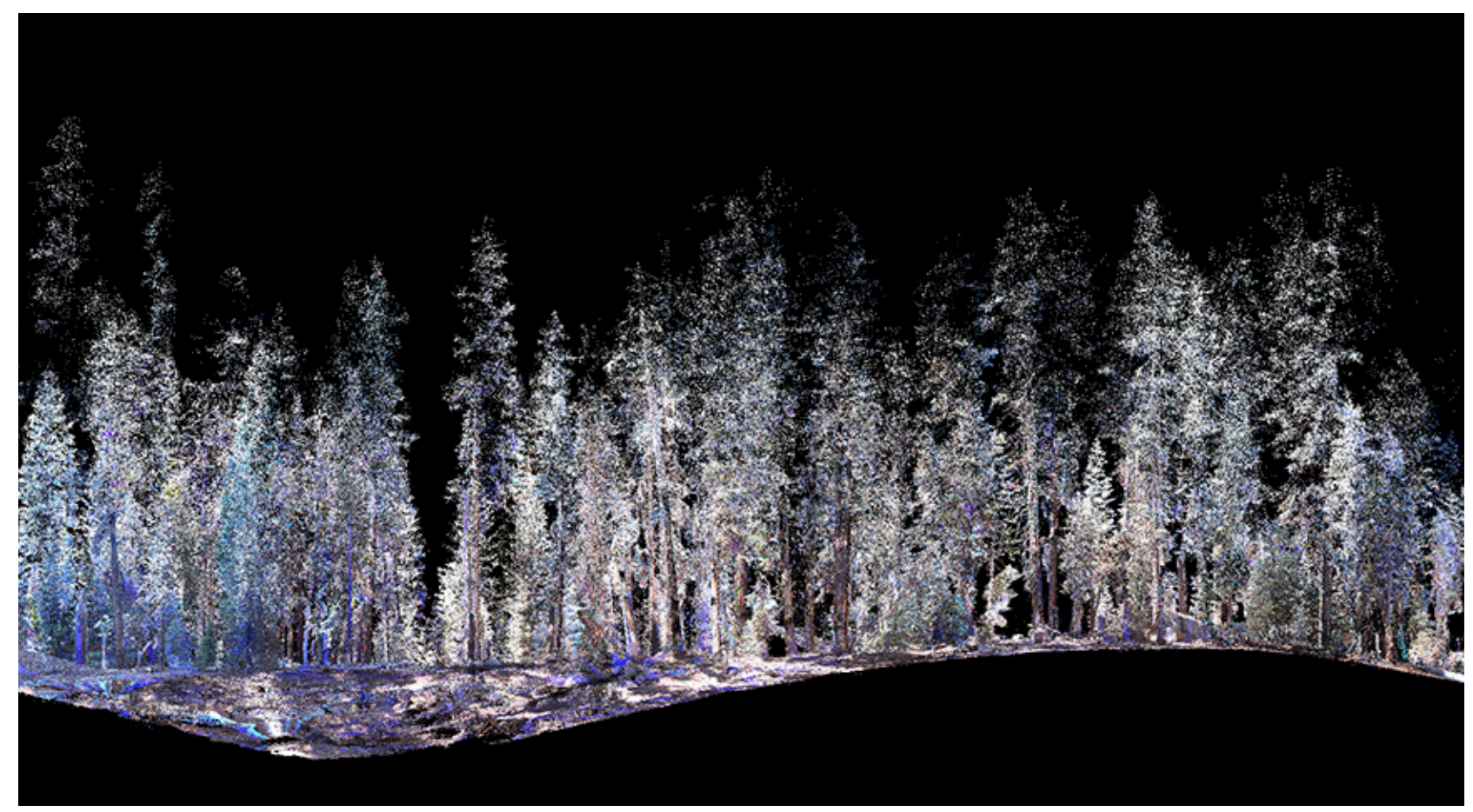

Figure 1: The digital forest is a point cloud representation of my red fir study site, located in California's Sierra Nevada. Image courtesy of D.S. Christianson.

Using auto-ethnographical (Holbrook 2006; S. Brown 2007) and interactiveresearcher introspection (Ellis, Adams, and Bochner 2011) approaches, ${ }^{1} \mathrm{I}$ describe my use of a new digital, visual representation of the forest in my ecological research and place it in the tradition of scientific visual representations. Then, I assess the scientific opportunities that using such technologies affords, in my case by fostering a conceptual model of the forest that is more malleable than commonly used representations. Leveraging STS critiques of representations, especially visual representations enabled by technology, I examine the potential risks of this new type of visual representation. Finally, I offer a framework for ecologists to harness the opportunities of new visual technologies responsibly. ${ }^{2}$

\section{Background: The Many Ways to (Scientifically) Represent a Forest}

Understanding of cognitive processes suggests that visualizations are an important form of representation. First, visual communication often results in very fast cognition (Baird et al. 1993). Compared to verbal descriptions of a concept, visual representations can be better understood because the concept

\footnotetext{
1 I hope to (1) illuminate insights not accessible to an outside researcher and (2) exemplify a practice of self-reflection that I posit will benefit the field of ecology. I also loosely follow Geertz's (1973) notion of “thick description," in which I attempt to provide a detailed account of my ecological practice so that the reader can better assess my claims regarding scientific visualization practices.

2 This work is drawn from Danielle S. Christianson, "Fine-Scale Environmental Variation in Mountain Landscapes: Quantitative Approaches, Influences on Tree Recruitment, and Implications for Scientific Visualization” (PhD diss., University of California, Berkeley, 2016), https:/lescholarship.org/uc/item/80142362.
} 
is already constructed (Miller and Burton 1994). Another benefit of visual communication is that visual understanding is an innate process (Hewes 1978, as cited in Seels 1994). Human physiology is literally hardwired for visual input: 75 percent of information entering the brain is from the eyes, and the optical nerve comprises 38 percent of the fibers entering or leaving the central nervous system (Hansen 1987, as cited in Barry 1994). Visual understanding is our primary form of learning as children (Hartin 1994; Mathewson 1999). Feldman (1976, as cited in Hartin 1994) suggests that we have to unlearn many of our childhood learning skills in order to transition to a language-based communication system.

Additionally, complex concepts can often be concisely communicated through visualizations as opposed to lengthy language descriptions (Braden 1994; Mathewson 1999). This is because visualizations can display an entire concept at once (Messaris 1997), whereas language-based communication is linear and piecemeal - that is, each word piece is arranged one after another. Its holistic, nonlinear representation makes visualization a multidimensional form of communication (Frascara 2001). Tufte notes that representing concepts over multiple scales is an important reason why visualization of complex concepts is successful (Tufte 2006).

Finally, visual representations are powerful because they provide evidence (Moser 1996; J. R. Brown 1996; Messaris 1997) or an experience of reality (Barry 1994). Latour (1990, 35) also notes the evidential qualities of visual representation: "You doubt what I say? I'll show you." Peirce incorporates the ideas of evidential representation in his framework of signs: icon, index, and symbol. An icon is a representation of an object or an action that still bears resemblance to the referent although it may be stylized; an index is a representation that is directly mapped to the referent; and a symbol is an abstract representation of the referent that almost always requires cultural convention for understanding (Peirce 1998).

Fundamentally, the majority of representation in scientific practice relies on collecting what Latour calls "immutable mobiles," the "things" a scientist goes and comes back with to convince others of a particular argument (Latour 1990). My ecological research, like many other studies, is focused on collecting quantifiable bits of the forest. My scientific goal was to understand what combination of environmental conditions influences tree seedling establishment - that is, what light levels, soil moisture, nutrient levels (all the things a seedling needs to survive) allow for seedlings to grow well. To study this question, I primarily collected quantitative information about the seedlings themselves and the physical environment around them (figure 2). To be effective pieces of evidence according to Latour, these quantifiable bits or "data" must be immutable, mobile, flat, scalable, reproducible, recombinable, superimposable, integrable with written text, and mergeable with geometry 

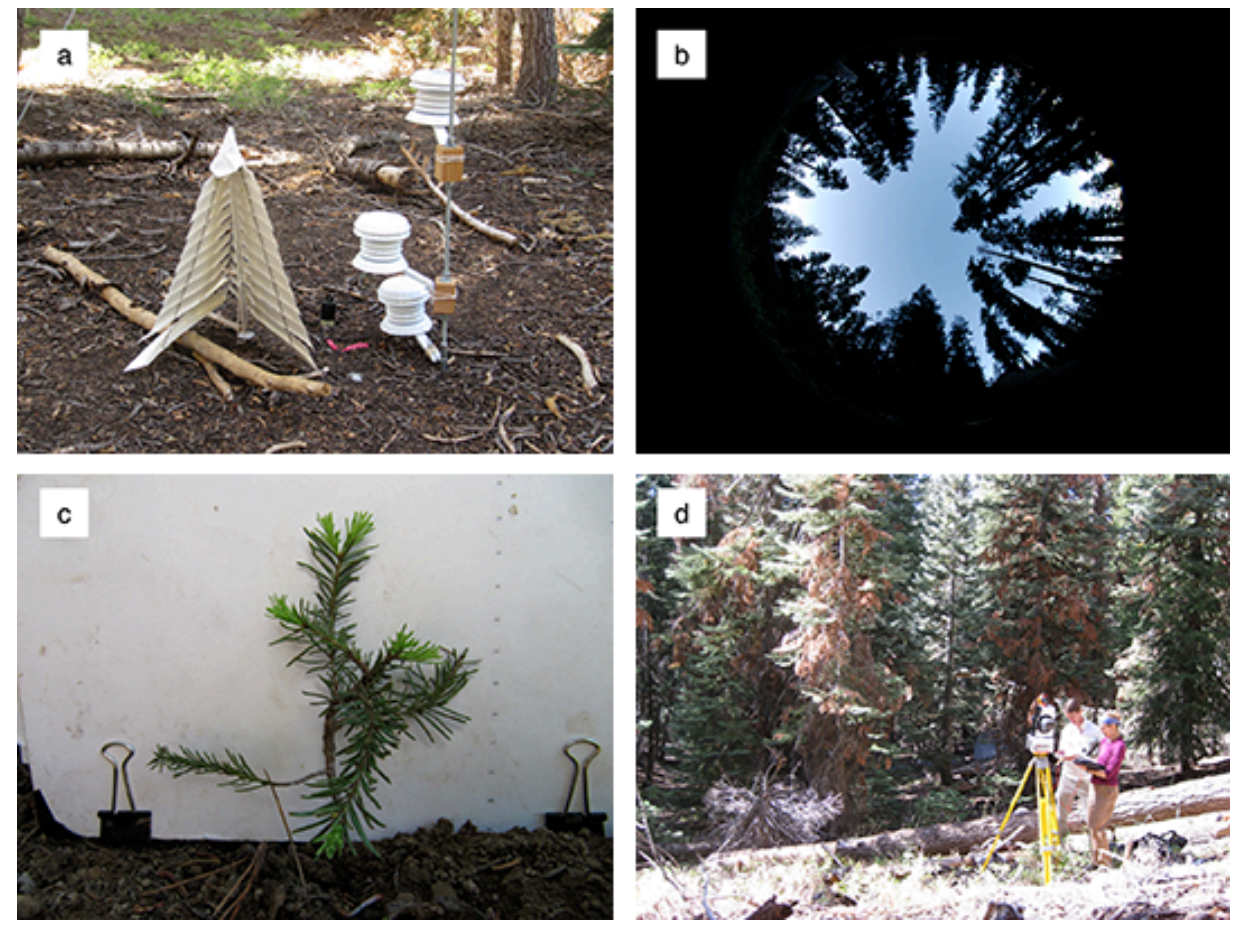

Figure 2: A sample of the type of information that I collected in my ecological study. (a) One of 225 sample locations within the $640 \times 20 \mathrm{~m}$ study site: manually deployed piche evaporator under triangular radiation shield measuring potential evaporation; soil moisture access tube (black cap) used to manually measure soil moisture; automated sensors in cylindrical radiation shields measuring the vertical air temperature and relative humidity profile; automated sensors (marked by silver tag just below pink flagging) buried $5 \mathrm{~cm}$ below the surface measuring soil temperature. (b) I took hemispherical "fish-eye" photographs of the forest canopy at those same 225 locations. (c) I manually collected tens of thousands of measurements on thousands of tree seedlings. (d) I scanned my study site with a terrestrial laser scanner (colleagues are configuring a scan with the I-Site 4400 scanner and handheld controller tablet).

Images courtesy of D.S. Christianson.

(i.e., made 2D) (Latour 1990, 44-46). Many of these characteristics are important so that the collector can organize the data into a simplified representation of the observed phenomenon.

Latour calls this organization a "cascade of cascades" in which the scientist makes sense of a phenomenon. Latour is referring to a series or hierarchy of reduction processes that combine the data into a smaller set of knowable entities (Latour 1990). Classification (Bowker 2008; Bowker and Star 2000) and/or standardization (Scott 1998; Edwards 2010) play an important role in these reductions. In Latour's data requirements, classification and standardization are especially important to make the data scalable, recombinable, and superimposable-that is these practices make data comparable to other data or existing data.

Haraway cautions that these reductions of the studied entity, especially those enabled by technologies, are partial perspectives. With the extension of their senses, scientists are easily seduced into a practice that regards technologically enabled perspectives as complete and objective. What Haraway calls a "godtrick" allows scientists and users of scientific information to "transcend . . . all limits and responsibility" (Haraway 1991b, 190). By understanding that all representations, including nonmediated experiences, are partial and by seeking 
many of them, scientists can recognize the limits to a particular perspective defined in part by the technology utilized and can seek to fill some of those gaps.

Barad extends Haraway's framework through her concept of agential realism, in which phenomena are understood in local contexts that are particular to the observed, the observer, and the apparatuses used in the act of observing. As illustrated by the uncertainty principle, ${ }^{3}$ the observer and the observed are both essential to create understanding through "intra-actions" that are additionally constrained by any apparatus used (Barad 2003). With this framework, Barad questions critiques of representations that focus on whether they adequately capture an external truth (traditional realist epistemologies) or how they are shaped by cultural forces (social constructionist epistemologies). Instead, with agential realism, Barad embeds representations within a dynamic performative understanding of the world that comes into being through the emergent "intra-actions" of the observed, the observer, and the apparatus employed. ${ }^{4}$ Because this understanding is not predefined by an exterior truth or societal norms, scientific knowledge practice becomes more objective and open to reconfiguration with new perspectives.

Similarly, Gabrys suggests framing new sensing technologies as equal components of environments that concresce through the process of sensing. New arrangements of humans, more-than-human sensors, and organisms generate new experiences and occasions for understanding environmental processes (Gabrys 2016). Sensors affect what processes are discoverable, and in turn, place and organisms influence the "tuning" of the sensors. Gabrys (2016, 271) posits that although many new technologies are programmed to execute specific procedures, experimental collaboration with these sensing technologies can lead to "indeterminate environments, entities, and relations." The resulting speculation creates a sense of adventure and openness, which in turn creates "opportunities for creative and practical as much as analytical engagements" (Gabrys 2016, 272) for understanding what matters and what is of concern in the environment.

Scientific visualization is being redefined continuously by ongoing technological development. An iconic example is the optical instruments that make the small large (microscopes) and the distant near (telescopes). Technologies often expand the human senses, bringing the tiny, the distant, the large, the fast, and the slow into human perspectives and also into forms that scientists can manipulate. I define new visual representations as a collection of "immutable mobiles" that are primarily understood through our visual senses

\footnotetext{
3 The uncertainty principle is a mathematical inequality that limits the knowledge of pairs of physical properties-for example, the position and momentum of a particle.

4 I use Barad's term "intra-actions," or the relationships between the observed, the observer, and the apparatus that become defined as an understanding of a phenomenon emerges. Because these relationships are not predefined and develop within the phenomenon's description, Barad distinguishes them from "interactions," relationships between predefined entities (Barad 2003).
} 
and require training outside established practices to produce the representation and/or engage with it. Although some visual representations go beyond the visual, such as virtual realities that invite corporeal and affective engagement, I focus this work on the visual effects of new technologies because of their importance to comprehension and cognition.

While enabling insights into the world and improving the human condition, the ability to see beyond human senses has been critiqued. For example, Haraway posits that these technologies, as generated from the industrialmilitary complex, evoke a practice of observer dominance over the observed. The observed become flattened things, similar to Latour's ideal immutable mobiles, that the observer can manipulate and recombine to her desire. In the process, responsibility toward the observed is lost (Haraway 1991b). Similarly, Barad (2003) suggests that failure to recognize the "intra-actions" that these technologies enable blinds the observer to full understanding because the observer is unaware of what she may not be observing. Myers (2014) describes scientific practices in which technological metaphor shapes both the types of discoveries that are made and the group of scientists that are making them. Finally, Vertesi (2014) warns that technologies can inscribe perspectives that become so ingrained within a scientific practice that they become the way to see the observed rather than a way to understand it.

It is in this scientific practice of visual representation, strongly shaped by technological capabilities, that I explore my use of new technologies, terrestrial laser scanning and associated 2D and 3D visually based technologies, in my ecological study of forest regeneration. To situate myself in this work, I am motivated by a desire to better understand and help mitigate the impacts of climate change on the entire planet (human and nonhuman). In addition to my ecological research, I studied climate change communication in the hope of finding effective methods to better translate my scientific findings to policymakers and the broader public. As my inquiry into climate change communication and (in)action proceeded, I came across research suggesting that more scientific evidence, as presented, was insufficient by itself to promote action. Seeing that the science was not enough, I turned toward critical theory and the social sciences to improve my own understanding of the scienceculture interface.

I delved into STS and feminist theories that critiqued the quantitative sciences for objective study of subjects that privileged technological approaches, especially ones that enabled the collection of high-resolution spatiotemporal data. I began to question my own scientific practice and discovered that I too had seen the forest as the object of my study and had seen only the benefits of the technological approaches that I employed. STS and feminist frameworks allowed me to consider the subjective and partial perspectives of scientific approaches to more fully understand how I was experiencing and making scientific sense of the forest. Because ecological science often produces 
recommendations that impact ownership and governance of the natural world as well as influence what types of knowledge count, I feel that it is critical for ecology as a discipline to examine its epistemological practice.

\section{Creating a Digital Forest}

To create a digital representation of my forested study site, I used laser scanning, also known as light detection and ranging (LiDAR) technology. ${ }^{5}$ The scanner fires a low-intensity laser, which hits a solid object and bounces back to the instrument, where a sensor detects it. The time it takes for the laser to return to the instrument is converted to a distance. The scanner repeats this process one million times, each in a slightly different known direction, radiating outward from the instrument in a donut-shaped volume. From the known direction and distance to a solid object in that direction, $\mathrm{XYZ}$ coordinates are calculated. At my $640 \times 20 \mathrm{~m}$ study site, I conducted eightyseven scans that I then merged together to form a collection of points in $3 \mathrm{D}$ space called a point cloud. The scanner also collected the red, green, blue (RGB) color information from a simultaneously collected photograph.

One of the visualization platforms that I used to analyze the point cloud is I-Site Studio (figure 3) software developed by the scanner manufacturer. It is essentially computer-aided design (CAD) software that renders points instead of traditionally rendered surfaces in $3 \mathrm{D}$, although the representation is displayed in $2 \mathrm{D}$.

I also analyzed the point cloud in the UC Davis KeckCAVES 3D immersive environment for visualizing and analyzing various forms of $3 \mathrm{D}$ data (figure 4). I used LIDARViewer, freeware developed for visualizing point cloud data in the Computer Aided Visualization Environment (CAVE) and other virtual platforms (Kreylos, Bawden, and Kellogg 2008). The CAVE is housed in the Geography Department at UC Davis and is primarily used for geological applications, although microbiological researchers and artists have also used the CAVE (UC Davis KeckCAVES 2015; Myers and Dumit 2011). While point clouds are becoming more common in ecological study, especially airborne laser scanning (Dassot, Constant, and Fournier 2011), this is the first project, of which I am aware, to use a CAVE to analyze point cloud data for ecological application.

The digital forest viewed in either $2 \mathrm{D}$ or $3 \mathrm{D}$ extends aspects of more common scientific technologies. The point cloud visualization is composed of the observed data, although theory laden, and it is indexical, which conveys authenticity as evidence (Messaris 1997). Perhaps one of the most novel aspects of the digital forest is that it merges spatial scaling with multiple viewing angle possibilities. The viewer breaks free of the within-forest perspective of typical 


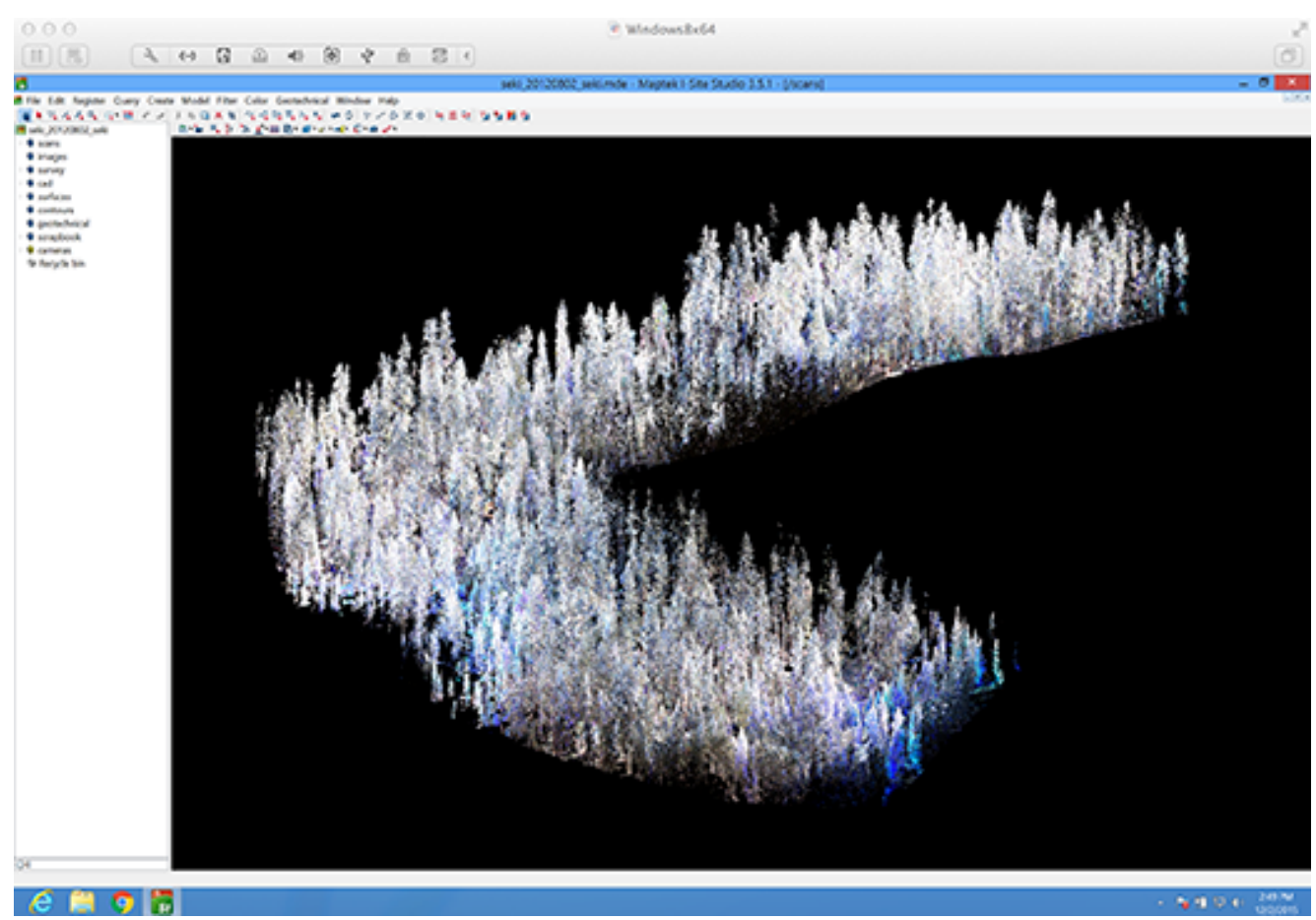

Figure 3: In I-Site Studio software, the user can zoom in and out, rotate the point cloud, add points, select points manually or via selection rules, modify groups of points (e.g., delete points, move point position, change point color), model lines or surfaces, etc. Other datasets, like my surveyed georeferenced tree seedling location data, can be imported to analyze with the scanned data.

Image courtesy of D.S. Christianson.

forest experience (compare video S1 and video S2). She is able to see the forest as a whole, from a bird's-eye view all the way down to subhuman perspectives, passing through the human scale. And she is able to take these relative perspectives from any view. This is unprecedented for a representation of a natural system that is based on observations. In the next section, I expand on how these new perspectives on a forest system may lead to new scientific insights.

\section{New Understandings of the Forest}

\subsection{Multiple spatial scales from any perspective}

The digital forest can be explored at any spatial scale from any perspective (video S2). As the video begins, the view is beyond the human, allowing for the entire forest study site to be seen simultaneously. The scientist can take this broad-scale view from any perspective-from above, from the side, or from below. The ability to visually isolate the forest study site in an external representation is also an unusual perspective not easily available in traditional representations like photography or satellite imagery. Zooming into the digital forest, the viewer can experience it at normal human and smaller scales. Myers and Dumit (2011) hypothesize that limitless scaling capability and degrees of freedom give researchers space for creativity in scientific discovery. 


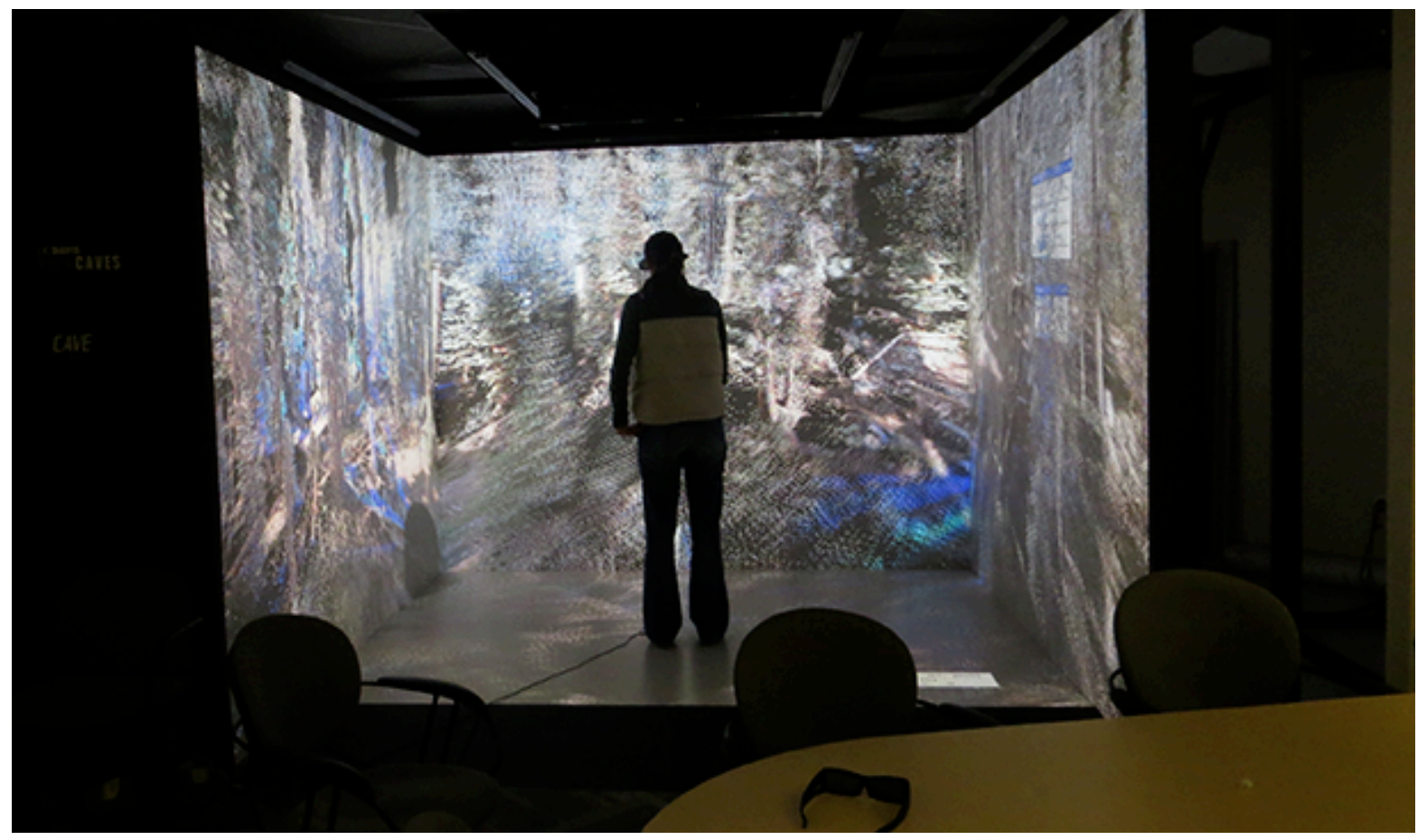

Figure 4: The KeckCAVES is an immersive 3D environment (i.e., virtual reality). The space is roughly a $2.5 \mathrm{~m} \times 2.5 \mathrm{~m} \times 2$ $\mathrm{m}$ volume with projection walls on three sides and the floor, upon which stereographic imagery is projected. While wearing $3 \mathrm{D}$ glasses, the user experiences seamless imagery in which they are embedded. A head-tracking device is worn so that the images remain fixed while the user moves within the image. The user can zoom in and out and rotate the image in any direction.

Image courtesy of Cleo Woelfle-Erskine.

In my ecological study, I used the unique perspectives afforded by the digital representation to extract the location and size of the reproducing trees, ${ }^{6}$ which I ultimately used to assess the influence of forest stand structure characteristics on tree seedling presence and absence. ${ }^{7}$ Common acquisition of this type of data would entail georeferencing each tree individually and measuring its circumference with a tape measure. ${ }^{8}$ Given time and resource constraints in collecting measurements during the summer field season, I could not have collected this information over the necessary area surrounding the study site.' Instead, I developed a new method to extract the location and size of each adult tree that begins with selectively viewing only a portion of the forest: a $0.5 \mathrm{~m}$ thick slice of points centered at $1.375 \mathrm{~m}$ from the ground surface. ${ }^{10} \mathrm{I}$ then viewed these points from a top-down perspective, from which I could see the trunks of the trees represented by circles and arcs (figure 5). I measured

\footnotetext{
6 Adult trees greater than $30 \mathrm{~cm}$ diameter at breast height $(\mathrm{DBH})$.

7 Examples of forest stand structure characteristics are distance to nearest adult tree and seed density, the sum at a particular location of seeds produced and dispersed from each nearby tree.

$8 \mathrm{DBH}$ is calculated by measuring tree circumference at $1.375 \mathrm{~m}$.

9 Red fir seed can be dispersed up to $40 \mathrm{~m}$ from the tree; thus I needed to know the locations and sizes of all adult trees in a border area surrounding the study site. This border area needs to be at least $30 \mathrm{~m}$ wide to accurately assess seed density.

10 To model the forest surface in I-Site Studio, I selected the lowest point on a $1 \times 1 \mathrm{~m}$ grid. I used I-Site Studio algorithms to model a surface from these lowest points. Automated and manual postprocessing is required.
} 


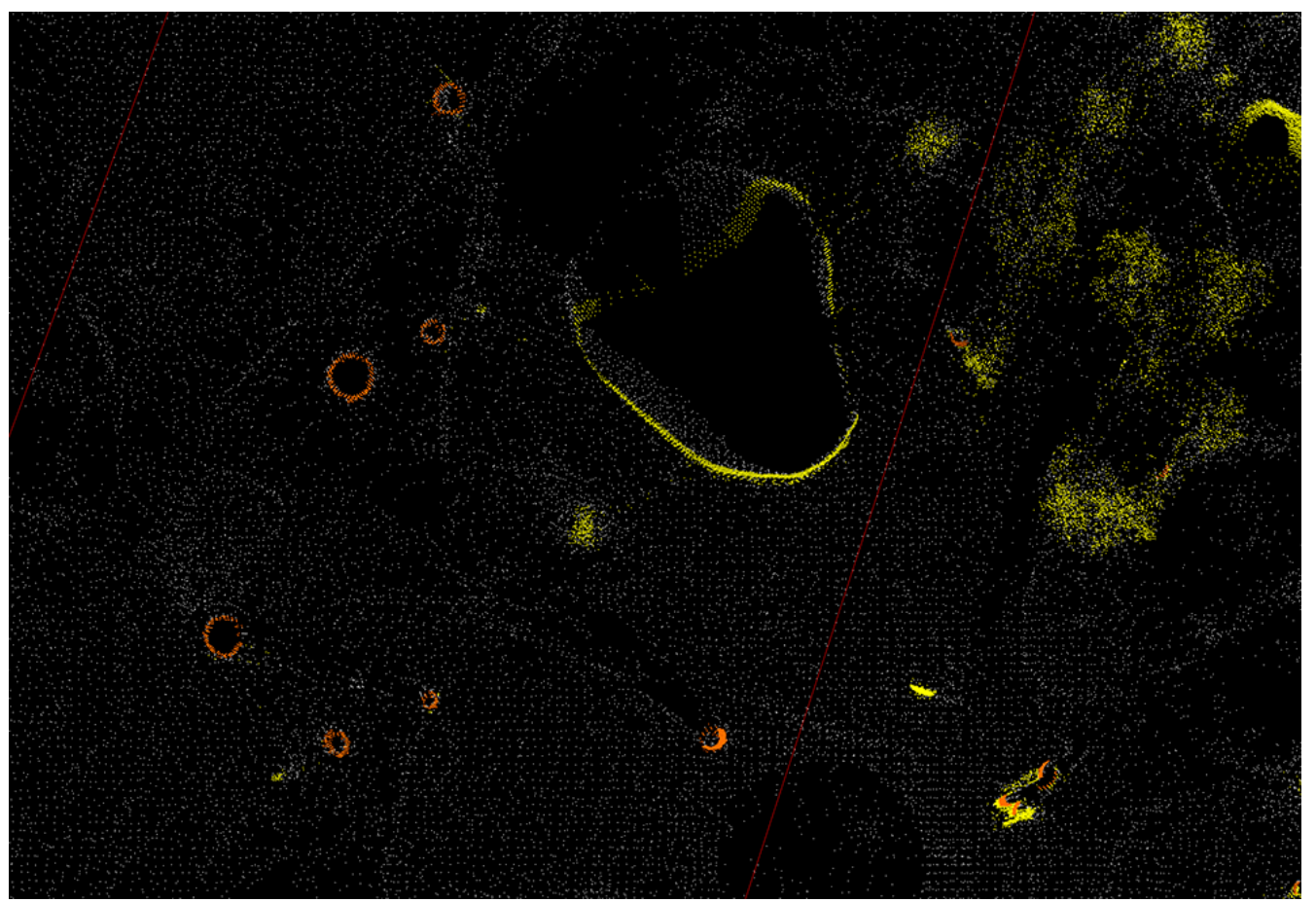

Figure 5: A portion of the digital forest within $1.5 \mathrm{~m}$ of the ground surface (i.e., all points above $1.5 \mathrm{~m}$ are removed). The $\mathrm{DBH}$ slice with points $1.375 \mathrm{~m}$ from the modeled ground surface are colored yellow and orange, with orange points indicating an adult tree.

Image courtesy of D.S. Christianson.

the diameter at breast height $(\mathrm{DBH})$ of these point trunks by fitting a circle to the points, and I used the center of the circle as the location of the tree. Via the novel perspectives available in the digital forest, I was able to acquire information that was unavailable to me using established methods.

However, using the DBH slice to quantify the size and location of the adult trees was problematic because I could not distinguish living from dead trees within the slice of $\mathrm{DBH}$ points. I also could not make the distinction when viewing the full point cloud in $2 \mathrm{D}$ with I-Site Studio. The unique viewing perspective enabled by the KeckCAVES allowed me to rapidly distinguish between the two (video S3). Using the KeckCAVES immersive environment, I inspected the forest scaled so that the tallest trees were $\sim 50 \mathrm{~cm}$ tall and oriented so that the trees were coming out of the vertical walls-that is, I was looking straight out in front of me but down into the forest. From this perspective, I could easily determine which trees were obviously dead (broken snags or no foliage). To do so, I often moved around the data so that I could create new views. My experience supports Myers and Dumit's observation of scientists working in the CAVE: "By changing their relationship with the object, they keep opening up new views” (Myers and Dumit 2011, 251).

\subsection{Lively interactions with the forest}

New perspectives, in terms of both viewpoint and spatial scale, enabled me to have new types of interactions with my forest study site. The interactions I had with the forest when extracting the location and size of the adult trees included 
a series of experiences: living forest $\rightarrow$ point cloud in $2 \mathrm{D} \rightarrow$ point cloud in $3 \mathrm{D}$ $\rightarrow$ living forest $\rightarrow$ point cloud in 2D. I first scanned the forest while actually in it. Then, I extracted the location and size information in $2 \mathrm{D}$ as described in the previous section. I turned to the $3 \mathrm{D}$ environment of the KeckCAVES to distinguish between dead and living trees. I needed to return to the field to verify ambiguously represented trees and to look for trees whose trunks at $\mathrm{DBH}$ height were not captured in the point cloud. Back in the living forest, I found several trees that I had not been able to identify in the point cloud. I was able to mentally combine $2 \mathrm{D}$ maps of the $\mathrm{DBH}$ slice with tree patterns in the field to estimate the missing tree locations. With these field-based estimates, I returned to the 2D I-Site Studio to map their $x y z$ coordinate locations in the georeferenced data. It was these series of new interactions, one leading to the other, that enabled me to fully assess the adult forest stand structure.

The digital form of the data along with its $2 \mathrm{D}$ and $3 \mathrm{D}$ representations allowed a responsivity, in which I as a researcher evolved with the data processing. Myers and Dumit describe this coevolution as a fundamental aspect of the benefits of interactive representations by observing a geologist working in the KeckCAVES:

As the geologist reaches out and hesitates, not knowing yet what or where or how to measure, we observe both her subjectivity and the objectivity of the phenomena wavering. The scientist is no longer the architect or choreographer in this experiment. There is no well-mapped experimental method: experimenter, instrument, data, and phenomena are all in the making. The result is that there are no clear-cut subjects or objects, until the final proof is rendered. (Myers and Dumit 2011, 247)

This responsivity and the coevolution of scientist and understanding provide opportunities for new understandings:

Similarly for CAVES researchers, the shock of swimming in a $3 \mathrm{D}$ environment is the "liveness"-the tangibility and multidimensionality - of the structures that had been so reduced in previous publications. They too are working with data whose scales and spaces and temporal dimensions are not easy to parse. They are faced with a slew of shifting questions: Where to look? How to look? What to look at? What counts as an interesting phenomenon? What might be an artifact? . . . For us, this dizziness demonstrates the openness of inquiry in the CAVES. (Myers and Dumit 2011, 254) 
My development of the methodologies to locate and size the adult trees supports Myers and Dumit's description of uncertainty leading to new understandings. It also supports Gabrys's (2016) claim that the indeterminate experiences of new sensor arrangements provide opportunities for creative engagements.

\subsection{Relearning to see the forest}

New spatial scales and perspectives and new interactions lead to new ways of seeing. Despite its evidential representation of the forest, engaging with the digital forest wasn't straightforward; it required the viewer to relearn how to engage with the forest. I had to change how I utilized visual references. In my case, my intimate knowledge of the living forest heightened the differences that I perceived when experiencing the digital forest.

A striking example of this contrast occurred during my first visit to the KeckCAVE. A short time into the experience, I realized that while I was seeing the forest as represented by a collection of bright points that formed tree trunks and foliage, boulders, down logs, and the rough forest floor in the darkness, I was mentally overlaying my memories of specific locations in full resolution and color onto the point cloud. In this way, I seemed to be merging these two sets of cognitive imagery. I built the capacity to hold this dual representation over time. In doing so, an important tool was relearning how to navigate in the digital forest. While in the living forest, I looked into the near distance to locate myself when disoriented. Initially, in the digital forest, I could not look into the distance to find references because (1) the points become indistinguishable from one another (figure 6) and (2) I had not yet formed new references in the digital representation. Thus, I would zoom completely out of the study site to acquire a top-down view. Based on my experiences with the living forest, ${ }^{11} \mathrm{I}$ identified the location to which I wanted to go and zoomed back in. Through this new form of navigation, I built new memories of the forest that came into being by processing the forest in collaboration with the $3 \mathrm{D}$ technologies and forest (Gabrys 2016).

Color also played an important role in my new understanding of the forest. During my initial interactions with the digital forest in both $2 \mathrm{D}$ and $3 \mathrm{D}$, the points were colored from a photograph simultaneously taken with the laser scan (video S4). Thus, many aspects of the forest are colored realistically. ${ }^{12}$ However, to complete most of my analyses, I needed to use color to help me focus on specific portions of the forest. To extract tree location and size, I colored all points not in the $\mathrm{DBH}$ slice a light gray and the $\mathrm{DBH}$ slice yellow

\footnotetext{
11 I believe part of my spatial understanding of the forest came from mapping the seedlings and reference markers in the living forest. I already had a conceptual framework of the relative locations of certain parts of the forest based on a top-down perspective from these $2 \mathrm{D}$ maps.

12 Because scans were made during the day, the exposure of the photograph could not compensate for the full range of light and dark patterns beneath the forest canopy. Thus, some atypical coloration occurs. This is most apparent in areas of overexposure that are recorded as whiteyellow and sometimes blue. The underexposed areas of the forest are colored dark blues and browns, which are not readily visible against the black background of the I-Site Studio and KeckCAVES backgrounds.
} 


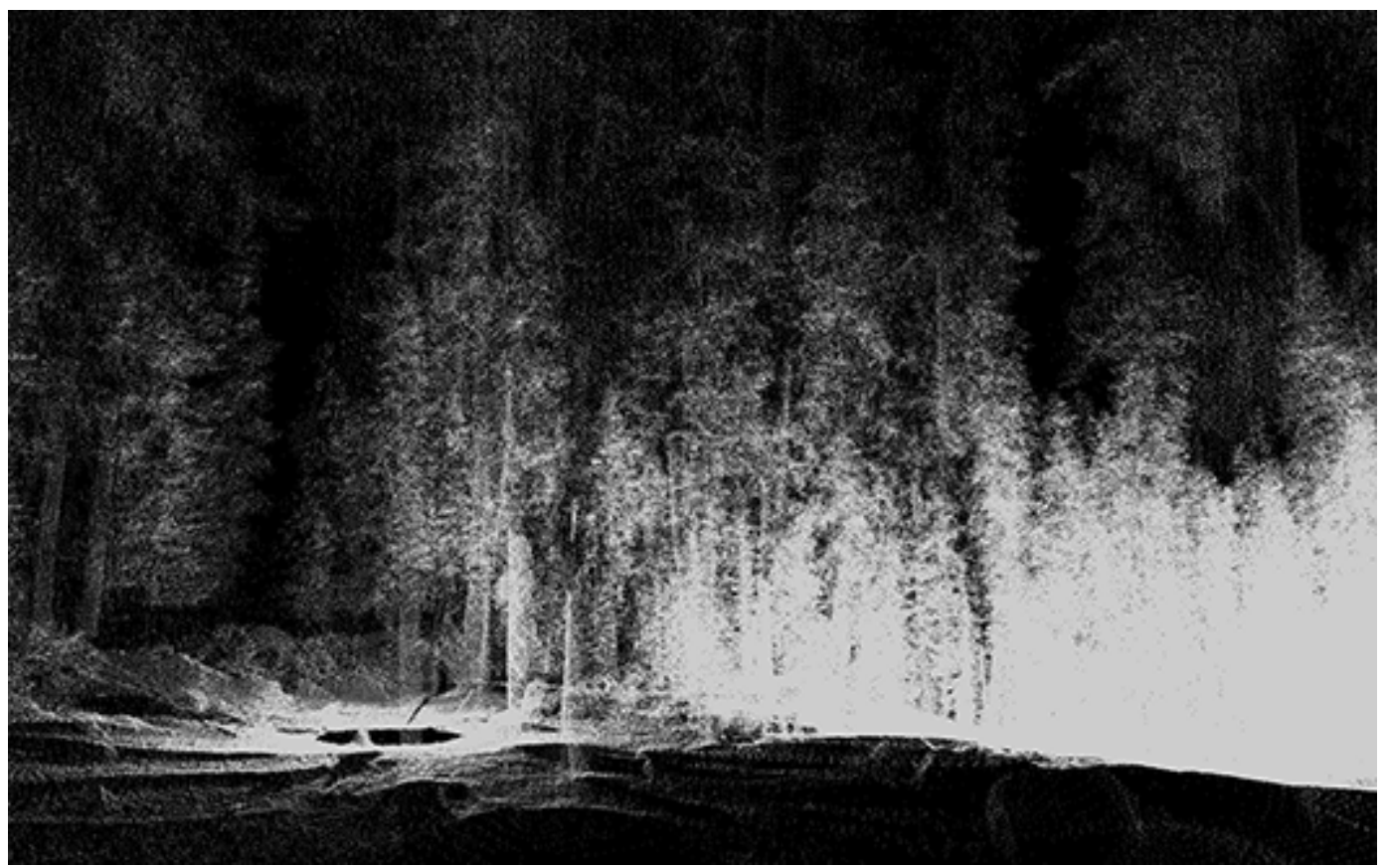

Figure 6: Digital forest as viewed in 2D I-Site Studio software. Points are indistinguishable from one another in the distance, especially when colored the same.

Image courtesy of D.S. Christianson.

(video S3). As I located and sized each tree, I changed the points belonging to the particular tree orange so that I could track which trees I had already processed. The difference in color allowed me to see the forest in a particular way that was useful to my analyses and not possible in the living forest. This example illustrates a form of inscription that allows not only me, the scientist, to understand the forest in a particular way but also others to view the forest in the way that I am seeing it. Vertesi highlights the inscription benefit of digital media in her discussion of scientists studying Martian soil with visual imagery: "drawing as' not only reveals new aspects of a visual dataset but also produces a 'seeing as' experience for other viewers" (Vertesi 2014, 29). As Vertesi suggests, I am "not passive, but rather actively compose the image into something meaningful through image-process practices" (Vertesi 2014, 24). However, I am not in complete control of the inscription. As I was tuning the digital forest to make meaning, the place and its organisms influenced my tuning and what aspects of the forest came into being (Gabrys 2016), as described in section 3.2.

What I did not expect in learning to see the forest in new ways was the embodied effects of working the CAVE. I did not anticipate the cognitive load of the CAVE itself. It was mentally exhausting learning to navigate the forest as a set of points. Initially, I mistakenly recolored the forest a light gray that made the forest too intensely bright. Additionally, I colored points of interest cyan and magenta, but in the sea of gray, I was squinting to find them. I eventually added additional points in specific patterns so that the color had some density to stand out against a medium-light gray point color. In addition 
to eyestrain due to miscolorations, it was tiring to look through the points to see something in the distance or at my notebook when recording notes. Also, because of equipment quirks, the image jumped in and out of 3D, which added to cognitive fatigue. ${ }^{13}$ Working in the CAVE was physically taxing as well. The CAVE is kept quite cool to provide an adequate environment for the five computers that run it; the constant whir of computers is ever present; and unlike when working in the living forest, I stood in the same position for hours. Thus, it took time for my body and my cognitive systems to be able to engage meaningfully with the digital forest, a place that is both familiar and foreign.

Once comfortable working with the digital forest and inscribing particular views to facilitate understanding, I approached my ecological studies differently. What's similar is that I can use the point cloud like other methodological tools to extract quantitative information, Latour's immutable mobiles, from the forest system. What's different is that through that process of interacting with these data, I have experienced a new conceptual model of the forest that is more malleable than most traditional ecological tools. The point cloud is a $3 \mathrm{D}$ quantitative model of the forest that can in turn be quantified itself, countering Latour's $(1990,29)$ contention that reduction and $2 \mathrm{D}$ reconstruction of nature is necessary: "Scientists start seeing something once they stop looking at nature and look exclusively and obsessively at prints and flat inscriptions. In the debates around perception, what is always forgotten is this simple drift from watching confusing three-dimensional objects, to inspecting two-dimensional images which have been 'made less confusing." The point cloud is a less confusing yet still complex $3 \mathrm{D}$ version of nature. In exploration of it, new creative uses await discovery (Myers and Dumit 2011; Gabrys 2016). As an addition to the living forest, my research opportunities, or field of view, so to speak, have broadened because the digital forest offers new inscription possibilities (color, enhancement, scale, perspectives) that are not available in the forest itself or via other established ecological tools.

\section{Looking between the Points \\ 4.1 A god-trick}

With the ability to interact with the forest from any perspective and at any scale in the digital forest, I assumed omnipotent control over it. I could slice the forest into pieces, view it from above, and color it as I desire. I brought the forest within my technical tool kit, and it is at my disposal. This reconfiguration is in sharp contrast with an experience of the living forest, where I was at the mercy of the uneven terrain, bitter cold mornings, fixed limited view from the forest floor, daylight hours, and mosquito attacks. Haraway (1991b, 189) describes the dangers of this omnipotent god-trick, luring one into believing 
that such perspective is the best and whole truth: "Vision in this technological feast becomes unregulated gluttony; all perspective gives way to infinitely mobile vision, which no longer seems just mythically about the god-trick of seeing everything from nowhere, but to have put the myth into ordinary practice." She argues that instead, many partial perspectives are necessary to fully understand the entity under investigation and one's relation to it: "objectivity turns out to be about particular and specific embodiment, and definitely not about the false vision promising transcendence of all limits and responsibility. The moral is simple: only partial perspective promises objective vision" (Haraway 1991b, 190).

Latour also warns against the types of omnipotent manipulation at my fingertips in the digital forest. He argues that such manipulation is in part what gives scientists and engineers their authority: "This trivial change of scale seems innocuous enough, but it is the cause of most of the 'superiority' of scientists and engineers: no one else deals only with phenomena that can be dominated with the eyes and held by hands, no matter when and where they come from or what their original size" (Latour 1990, 44-46). Do I feel domination over the forest system through this work? No. During my extensive experience working in the living forest, the forest system asserted its dominance regularly, as previously described. ${ }^{14}$ Following Haraway's argument, I have several partial perspectives from which to build an understanding of the forest. So, then, what is there to worry about?

Bringing entire ecosystems, such as a forest, inside our technological tool kits to be manipulated will become routine with technologies like terrestrial laser scanning and immersive 3D environments. As the technologies and the data become more common, scientists will have access to these omnipotent capabilities without necessarily acquiring the experience of the living place. The partial perspectives that I gained through required activities of collecting the data may have to be voluntarily sought by others. That they would do so is unlikely given today's scientific practice in which secondhand data usage is rarely reexamined by the user in the initial observation context.

This secondhand data usage with representations like the digital forest also troubles Barad's agential realist epistemology, in which understanding emerges from "intra-actions" between the observed, the observer, and the observing apparatus. The specific context of the "intra-action" defines the observed and the observer: " . . . an agential cut effects a local separability of different 'component parts' of the phenomenon, one of which ('the cause') expresses

14 Readers may question whether this response is because I have read Haraway and Barad, but I don't think so. Fieldwork at the site is always contingent on workable conditions; I have had enough of my plans go awry due to things beyond my control (e.g., uncooperative weather, downed trees burying sensors, bears disrupting measurements) to know that I would never dominate my interactions with the forest. What the digital forest did offer initially was a security blanket of sorts. I thought that by capturing a 3D representation of the forest, I would be able to easily return to the digital forest to rectify measurement inconsistencies. However, as I worked with the data, this assumption turned out not to be straightforward, as I describe in the following section. 
itself in effecting and marking the other ('the effect'). . . what is important about causal intra-actions is the fact that marks are left on bodies. Objectivity means being accountable to marks on bodies" (Barad 2003, 824). When interacting with the digital forest, especially without partaking in the collection of data in the field, the scientist's emergent understanding is no longer defined from "intra-actions" between the observer and the living forest. The scientist is "marking" the point cloud (e.g., new perspectives, inscribed color), and the point cloud is marking the scientist (e.g., new digital memories of the forest, mental and physical impacts). Whereas my intra-actions with the digital forest are additionally grounded in the data collection and intimate experience with the living forest, it is very unlikely that the secondhand observer is marked by the living forest via the digital representation. Thus, the living forest loses its agency in Barad's sense.

The risk is that human control over natural systems is reinforced in a new form that is extremely visceral and in which the living forest does not affect the scientist directly. Working with the digital forest, especially in the $3 \mathrm{D}$ immersive environment, imparts a feeling of total control over the forest system, which at some level seeps into our consciousness, especially if unchallenged. Bowker (2008, 153) suggests that "as the representation becomes internally more manipulable, it becomes externally more apparently real.”

\subsection{An incomplete model}

The fine-scale resolution of the scanning technology creates a much more spatially continuous representation of the forest than is commonly found in ecological studies. The resolution is fine enough that we can see specific elements within the forest (video S4). The realistic indexical imagery imparts the sense that the digital forest is an exact copy of the living forest, similar to photographic imagery that with the correct exposure and so on is a visually exact $2 \mathrm{D}$ replication of reality. ${ }^{15}$ The digital forest is an enhanced representation as its indexicality lies in the 3D structure, upon which realistic color can be overlaid. ${ }^{16}$ However, the $3 \mathrm{D}$ structure is not an exact copy; it is a theory-laden modeled representation of the living forest that contains error.

In addition to human-based inconsistencies, these data have important inherent omissions. First, the digital forest is a discrete representation, with points that sample the surfaces present in the landscape. The point density is such that small, airy forest features, like tree seedlings (ironically, the foci of my research), are not captured. Secondly, because the laser-based technology

15 I am thinking of photographic imagery as follows. A viewer is looking out of a window with her gaze in a fixed direction. Photographic equipment could capture an identical visual representation of whatever is viewable through the window so that disregarding depth information, the viewer would be presented with the same visual input.

16 As noted earlier, the color can be changed, which can challenge the realistic representation but not remove the underlying quantitative structural mapping of the living forest. 
captures only surface features, there is no information from the inside of forest entities, like tree trunks or rocks, or from important underground structures like roots. Even with better scan coverage, it is impossible in a complex landscape like the forest to eliminate occlusions and capture every surface. In addition to portions of the physical landscape and flora that are omitted, so too is much of the forest fauna. Thirdly, the digital forest is a single representation in time. No change in the forest structure itself is captured. Over the course of my study period (2009-13), tree mortality and fall significantly changed the forest stand structure. These changes affect sun/shade (radiation) patterns, rainfall interception, and litter accumulation, all important factors affecting seedling survival and growth. However, these changes are not observable in the digital forest. Finally, the photographic coloring of the forest is distorted. Some areas are overexposed and appear ghostly white-yellow-blue, while underexposed areas are dark brown-green-black. The underexposed dark colors do not contrast with the black background of the $2 \mathrm{D}$ and $3 \mathrm{D}$ platforms and are essentially invisible. It was not until I started recoloring the points to highlight specific features that I discovered almost a third of the points.

Bowker articulates the challenges of classifying biological and ecological entities (Bowker 2008). Things that are difficult to describe, things that do not break up into natural units, and things that have no easy boundaries or are theoretically ill-defined often get left out because they cannot be quantified. The discrete nature of the digital forest at first glance suggests solutions to these classification challenges. We've already broken up this complex entity into quantifiable immutable mobiles! However, the points are still difficult to describe (e.g., is that one-year-old seedling a white or a red fir?), do not break up into natural units (e.g., is that $25 \mathrm{~cm}$ tall tree a seedling or a sapling?), and do not have easily defined boundaries (e.g., should the study site include the meadow or go around it?). Simple classification of the points into tree, shrub, rock, log, or surface remains a challenge both technically ${ }^{17}$ and manually, especially with insufficient point density.

Once things are not included, they "get ignored, and so receive an everdecreasing amount of attention" (Bowker 2008, 141). The digital forest is so enticing because with so much data, it is easy to forget that the representation is incomplete. The risk is that these incomplete representations become selfreinforcing. ${ }^{18}$ Once a representation is firmly established, the missing elements are even more likely to not be considered. In the case of the digital forest, the absence of time is a key missing element. More dynamic theoretical frameworks

\footnotetext{
17 Object classification in point cloud data is at the cutting edge of research. For example, Brodu and Lague (2012) develop methods for identifying vegetation from other surface features.

$18 " \ldots$. [A] set of data structures and information retrieval models are set up so that a particular, skewed view of the world can be easily presented. With these structures and models in place, it is easier to get funding and support for research that reproduces this view-your work will be understood more easily, you can make good use of material from cognate areas, and so forth. Thus, the world that is explored scientifically becomes more and more closely tied to the world that can be represented by one's theories and in one's databases: and this world is ever more readily recognized as the real world" (Bowker 2008, 151-52).
} 
have only recently superseded the concept of ecological equilibrium. It is especially important to incorporate dynamic elements in representations of long-lived forests, the poster children of ecosystems in equilibrium, especially in light of the many temporally dependent environmental threats (like climate change) facing humans and other species.

\subsection{Influence of inscription}

Inscription is one of a scientist's most important tools. By creating a representation that highlights particular features or phenomena in a representation, the scientist allows others to see as she does (Vertesi 2014). For example, in the digital forest, I used color to draw attention to the $\mathrm{DBH}$ slice as well as to indicate which trees were modeled. Even a more basic choice of color scheme influences how another viewer experiences the digital forest, as some points are essentially invisible in photographic color. The point cloud itself is also a type of inscription when compared to other forms of representation such as photography or my $2 \mathrm{D}$ sketched maps. Several risks arise when a particular inscription becomes ingrained in scientific practice.

Vertesi notes the pervasiveness of inscription through Galileo's drawings of the moon, arguing that his particular type of rendering "influenced future viewings, depictions, and theoretical understandings of the moon, blinding viewers to other aspects" (Vertesi 2014, 21). Representations can become so pervasive that a viewer no longer "sees as" but rather only "sees." Vertesi states further:

Representation in scientific practice is therefore not a question of creating an ever more true or singular image of an object. Instead, we should note how practical work with images shuts down other ways of seeing in order to focus on one aspect, one set of salient relationships. It is the role of the analyst to identify each image's inscribed and implied aspect, to note the representational choices that produce and reproduce that aspect, and to remind us that it could always be seen otherwise. (Vertesi 2014, 31)

Vertesi is, in effect, calling for Haraway's multiple partial perspectives and lays the responsibility of understanding the perspective on the analyst as both inscriber and viewer. Similar to Bowker's claim that entities that are hard to classify are more likely to be ignored, Latour (1990) warns that the uncollected (in Vertesi's language, the un-inscribed) are forgotten. Thus, Vertesi's call for awareness of other views is critical to inclusion of the many entities and characteristics of a phenomenon.

Myers also warns of a potential risk of an inscribed perspective in her description of the advantages of machine metaphor as a rendering of protein structures. In her observations of biological engineers, she notes that "By naturalizing and literalizing machines in the bodies of organisms and asserting 
the neutrality of visualization techniques, practitioners risk giving the impression that they are merely unveiling the underlying machinery of life" (Myers 2014, 168). In other words, the machine metaphor is itself the discovery, and other ways of knowing the proteins are no longer possible. Haraway (1991a) makes no distinction between human interpretation of the technological and the organic. Thus, technical metaphor as a tool and technical metaphor as the discovery may not be easily distinguishable. We must be on guard to not privilege one perspective to the exclusion of others.

I anticipate a similar risk with my digital forest, as it is representative of other big data that is increasingly growing in popularity in ecology and the biological sciences (Hampton et al. 2013; Leonelli 2014). Big data proponents claim that because big data captures an entire phenomenon (1) it removes the need for theory and models; rather, correlation is sufficient; (2) there is no longer a sampling bias; (3) messy but complete data yield truthful insights; and 4) context is not necessary to interpret statistical results or data visualizations (Leonelli 2014; Kitchin 2014). Critiques of these claims as applied in the environmental sciences are just starting to emerge (Leonelli 2014). Through my work with the digital forest, I add the following.

My digital forest, like other big data such as that derived from remote sensing and distributed sensor networks, is inherently discretized. As this trend toward big data continues, we risk replacing the continuous natural world with these datasets that by their very nature imply that if we just measure each individual piece of the environment, we can reconstruct it through modeling frameworks to gain understanding. While our ability to break the environment apart and reform it in simpler models has yielded important ecological understanding, the concern is that it may become the predominant, if not only, acceptable way to scientifically understand ecological phenomena. If so, a discretized, modeled framework of ecological systems may become the discovery itself.

\subsection{Limits to time and participation}

Access to highly technical methodologies can be inequitable due to costs. With the current costs of terrestrial laser scanning, it is typically available only to those with large funding sources, often at a select number of institutions. Even within an institution, widespread access can be challenging. ${ }^{19}$ The cost of the I-Site Studio software, which was necessary to transfer my data into a form that was usable with freeware, prevented me from utilizing my digital data for several years. I regained access only once the manufacturer created a free educational license.

\footnotetext{
19 I was part of a team that acquired a laser scanner donation to my university. It was difficult to find a party on campus willing to take legal and financial responsibility for such an expensive piece of equipment. Once we found those willing to do so, it was difficult to negotiate a rental policy that yielded financial access to students while assuring that the equipment integrity would be maintained.
} 
In addition to the costs, the required technical skills also cull the potential user pool. My digital forest required proficient use of surveying technology, $3 \mathrm{D}$ CAD software, Unix command line programming, and $\mathrm{R}$ programming. To potential users who have little to no technical expertise, these requirements might be a strong deterrent. Myers reports that the machine metaphor and technical methods that dominate research of proteins shape the community of researchers studying their biological function: "machinic renderings not only constitute molecular visions; they also reconfigure entire research programs, and, crucially, they inform 'who is recruited to do the work' of modeling life-as-machine” (Myers 2014, 162). Given that technological methodologies are already privileged (Bowker 2008), ${ }^{20}$ continued technological advancement may limit the partial perspectives that we collectively generate as a scientific community. ${ }^{21}$

\section{A Responsible Digital Ecology}

Along with other STS and feminist scholars, I applaud and encourage the continued development of technological scientific representations, such as my digital forest, as the potential for new understanding is great. The ability to scale and view the forest from any perspective, interact with the forest in real time, create new conceptualizations, and work with an indexical representation have opened new possibilities within my own ecological research. However, also with fellow scholars, I urge the ecological research community to be aware of the consequences of these technologies and use them responsibly. The risks of not doing so are too high. Through technologies like terrestrial laser scanning and $2 \mathrm{D}$ and $3 \mathrm{D}$ viewing platforms, we incorporate natural systems into our technical tool kits. We must be wary that we do not adopt omnipotent control over these systems, see them as complete representations, or see them as a single correct way to investigate an ecological phenomenon. Furthermore, we must be wary of the potential exclusion of participants in ecological research by privileging highly technical and cost-prohibitive methods.

Haraway and Barad provide paths for balancing these risks and rewards. Haraway argues that knowledge practice should be situated, meaning that one is aware of her relationship to the studied object and the choices that led to that particular perspective. By acknowledging the partial view, one can take responsibility for that view through an understanding of power dynamics, technological advantages and disadvantages, and other potential perspectives (Haraway 1991b). Barad suggests agential realism as a framework for acknowledging partial perspectives. She posits that the combination of the observer, the observed, and the instrument creates meaning and understanding. The scientist is in a partnership rather than in complete

\footnotetext{
20 "[T] $]$ hey (scientists) are more likely to get funding for using exotic, expensive tools" (Bowker 2008, 146).

21 Gabrys (2016) posits that new sensing technologies open a path for more involvement in determining the environment experienced and what matters environmentally, especially from citizen scientists. With increased availability of virtual reality 3D viewing platforms (e.g., Oculus Rift), digital experiences may indeed become more accessible to broader audiences.
} 
objective control. Through agential realism, the scientist actively acknowledges the partial perspective enabled by the technology in use and by the observed (Barad 2003).

For ecology in particular, recognizing the observed as a research partner is especially important as the observed themselves are living beings or integral to the processes being observed. Humans are intimately connected to these other lives by complex relationships through interactions with the physical world. Ecology is the study of these relationships and interactions, much of which is motivated by understanding our own survival amid the environmental impacts that we humans are increasingly making. What is our ethical responsibility as scholars toward these other beings with which our lives are intertwined? Western anthropology and similar social sciences have faced similar questions in the study of other human cultures. The response has been to break down perceptions of otherness and to train scholars to include these other humans as willing and sometimes active participants in the research itself. Learning from Barad, Haraway (including her later works, e.g., Haraway 2008), and Gabrys, ecologists can also utilize other works by scholars who question perceived differences with other species and suggest reconfigurations with our earthly coinhabitants (Rose 2011; Woelfle-Erskine and Cole 2015).

Also key to acknowledging the partial perspectives enabled by our technological tools is experience in the living system with as little technical mediation as possible. Although a partial perspective itself, it was my intimate knowledge of the forest gained through thousands of hours spent at my study site that enabled me to understand what was captured with the laser scanning technology and what was not, as well as how this digital representation afforded me a new conceptualization of the forest. While my intimate relationship was necessary for this critical analysis, thousands of hours are likely not required for a grounding in the living forest. But without such grounding, perception of the forest based primarily on the digital representation would likely be completely different. A colleague recently said to me in so many words, "Big data is the future of ecology," and further suggested that ecologists in the future probably would not need to go into the field. Visualization of the forest with digital data has the potential to alienate us from the living forest in a way that is troubling. As this type of visual representation becomes more available, ecologists will need to grapple with the allure of the ready-made virtual environs that calls the scientist to the desk rather than to the forest.

It may be naive to expect users of big data to experience the locations of observations personally or to form intimate relationships with the technologies that captured the observations. For example, understanding a satellite and the imaging technologies that produce remote sensing data is unrealistic. And it is physically impossible to experience all the places captured in spatially and temporally extensive remote sensing data collection. Additionally, the many hours that I spent at my forested site may not be possible for ecologists studying 
extremely remote or dangerous locations. Bowker (2008) suggests an alternative in which the metadata associated with compiling such a dataset capture the situated position. What this might look like is yet to be determined, could take many forms, and is likely to involve some iteration. The measures of successful implementation are also slippery. I have no easy prescriptions, but beginning a reflective conversation among ecologists is a start. Perhaps as a community, ecologists can strengthen our collective understandings of forests by situating binary perspectives, like my digital forest, among others, and can keep the seductive risks of new digital representations at bay.

\section{Supplementary Files}

High-resolution videos can be viewed at https://vimeo.com/showcase/ 6113477.

Video S1: $A$ Walk in the Forest (https://vimeo.com/346643637). Video from my red fir forest study site as I walk through about $30 \mathrm{~m}$ of the plot. The down tree with white bark can be seen in video S2 (1:00-1:16).

Video S2: Many Scales and Perspectives (https://vimeo.com/346644380). Computer screen video of the digital forest as seen in I-Site Studio Software. In the first portion of the video, the digital forest is isolated from its surroundings with a scale beyond human. The forest can be observed from any perspective. As I zoom into the point cloud, details of the trees, boulders, and forest surface can be seen.

Video S3: DBH Color Slice (https://vimeo.com/346645003). Video of the digital forest in the UC Davis KeckCAVES in which I distinguished between alive and dead adult trees. The $0.5 \mathrm{~m}$ thick slice of points at diameter at breast height $(\mathrm{DBH})$ are colored yellow, with points included for models of individual trees colored orange. Magenta numbers identify specific trees, and a $5 \times 5 \mathrm{~m}$ reference grid installed in the living forest is marked with cyan points. In the first portion of the video filmed with $3 \mathrm{D}$ glasses, the flickering light is an artifact of the video. In the second portion of the video, the image is double as it is seen without 3D glasses. In both cases, I am immersed in the data as evidenced by the projection on myself. Video: Cleo Woelfle-Erskine and Danielle Svehla Christianson. Reproduced with permission of the videographers.

Video S4: In the Digital Forest (https://vimeo.com/346645756). Video of the digital forest in the UC Davis KeckCAVES in which the point cloud is colored by the photograph taken simultaneously with the laser scans. The background sound is from the five computers and four projectors that generate the imagery. Video: Cleo Woelfle-Erskine and Danielle Svehla Christianson. Reproduced with permission of the videographers. 


\section{Acknowledgments}

I thank Alenda Chang and Meredith Tromble for encouraging me to question my ecological use of new media. I am indebted to Manisha Anantharaman, Anna Kantenbacher, and Cleo Woelfle-Erskine for formative discussions and comments on drafts. Additional thanks to Cleo Woelfle-Erskine for filming interactions with the digital forest at the UC Davis KeckCAVES. My thanks also to Joe Dumit, Oliver Kreyos, Mike Oskin, and M. Burak Yikilmaz for introduction to and assistance in the UC Davis KeckCAVES. Thank you to Maptek for supporting educational use of their laser scanning technologies. Finally, thank you to Sarah Richmond and Justin T. Minear, who endured three intense days of scanning the forest site. A Berkeley Atmospheric Sciences Center Graduate Fellowship supported the laser scanning field activities. 


\section{REFERENCES}

Baird, Russel N., Duncan McDonald, Ronald H. Pittman, and Arthur T. Turnbull. 1993. The Graphics of Communication: Methods, Media, and Technology. Orlando: Harcourt Brace College Publishers.

Barad, Karen. 2003. "Posthumanist Performativity: Toward an Understanding of How Matter Comes to Matter." Signs: Journal of Women in Culture and Society 28 (3): 801-31. https://doi.org/ $\underline{10.1086 / 345321 .}$.

Barry, Ann Marie Seward. 1994. “Perceptual Aesthetics and Visual Language.” In Visual Literacy: A Spectrum of Visual Learning, edited by David M. Moore and Francis M. Dwyer, 113-32. Englewood Cliffs, NJ: Educational Technology Publishers.

Bowker, Geoffrey C. 2008. Memory Practices in the Sciences. Cambridge, MA: MIT Press.

Bowker, Geoffrey C., and Susan Leigh Star. 2000. Sorting Things Out: Classification and Its Consequences. Cambridge, MA: The MIT Press. https://doi.org/10.7551/mitpress/6352.001.0001.

Braden, Roberts A. 1994. "Visual Verbal Relationships." In Visual Literacy: A Spectrum of Visual Learning, edited by David M. Moore and Francis M. Dwyer, 193-208. Englewood Cliffs, NJ: Educational Technology Publishers.

Brodu, Nicolas, and Dimitri Lague. 2012. "3D Terrestrial Lidar Data Classification of Complex Natural Scenes Using a Multi-Scale Dimensionality Criterion: Applications in Geomorphology.” ISPRS Journal of Photogrammetry and Remote Sensing 68 (March): 121-34. https://doi.org/ 10.1016/j.isprsjprs.2012.01.006.

Brown, James Robert. 1996. "Illustration and Inference." In Picturing Knowledge, edited by Brian S. Baigrie, 250-68. Toronto: University of Toronto Press. https://doi.org/10.3138/ 9781442678477-010.

Brown, Stephen. 2007. "Autobiography.” In Handbook of Qualitative Research Methods in Marketing, edited by Russell W. Belk, 440-52. Cheltenham, UK: Edward Elgar Publishing.

Christianson, Danielle S. 2016. "Fine-Scale Environmental Variation in Mountain Landscapes: Quantitative Approaches, Influences on Tree Recruitment, and Implications for Scientific Visualization." PhD diss., Berkeley: University of California. https://escholarship.org/uc/item/ $\underline{80142362 .}$.

Dassot, Mathieu, Thiéry Constant, and Meriem Fournier. 2011. "The Use of Terrestrial LiDAR Technology in Forest Science: Application Fields, Benefits and Challenges." Annals of Forest Science 68 (5): 959-74. https://doi.org/10.1007/s13595-011-0102-2.

Edwards, Paul N. 2010. A Vast Machine: Computer Models, Climate Data, and the Politics of Global Warming. Cambridge, MA: MIT Press.

Ellis, Carolyn, Tony E. Adams, and Arthur P. Bochner. 2011. "Autoethnography: An Overview.” Historical Social Research/Historische Sozialforschung 36 (4): 273-90.

Frascara, Jorge. 2001. “Diagramming as a Way of Thinking Ecologically.” Visual Language 35 (2): 164-77.

Gabrys, Jennifer. 2016. Program Eartb: Environmental Sensing Technology and the Making of a Computational Planet. Minneapolis: University of Minnesota Press. https://doi.org/10.5749/ minnesota/9780816693122.001.0001.

Geertz, Clifford. 1973. “Thick Description: Toward an Interpretive Theory of Culture.” In The Interpretation of Cultures, 3-30. New York: Basic Books. 
Hampton, Stephanie E., Carly A. Strasser, Joshua J. Tewksbury, Wendy K. Gram, Amber E. Budden, Archer L. Batcheller, Clifford S. Duke, and John H. Porter. 2013. "Big Data and the Future of Ecology." Frontiers in Ecology and the Environment 11 (3): 156-62. https://doi.org/ $\underline{10.1890 / 120103 .}$.

Haraway, Donna J. 1991a. “Cyborg Manifesto.” In Simians, Cyborgs, and Women: The Reinvention of Nature, 149-82. New York: Routledge.

_- - 1991b. "Situated Knowledges." In Simians, Cyborgs, and Women: The Reinvention of Nature, 183-202. New York: Routledge.

- - . 2008. When Species Meet. Minneapolis: University of Minnesota Press.

Hartin, John A. 1994. "Theoretical Foundations of Visual Learning." In Visual Literacy: A Spectrum of Visual Learning, edited by David M. Moore and Francis M. Dwyer, 5-29. Englewood Cliffs, NJ: Educational Technology Publishers.

Holbrook, Morris B. 2006. "Consumption Experience, Customer Value, and Subjective Personal Introspection: An Illustrative Photographic Essay.” Journal of Business Research 59 (6): 714-25. https://doi.org/10.1016/j.jbusres.2006.01.008.

Kitchin, Rob. 2014. "Big Data, New Epistemologies and Paradigm Shifts.” Big Data E'Society 1 (1): 1-12. https://doi.org/10.1177/2053951714528481.

Kreylos, Oliver, Gerald W. Bawden, and Louise H. Kellogg. 2008. “Immersive Visualization and Analysis of LiDAR Data." In Advances in Visual Computing International Symposium on Visual Computing 2008, edited by G. Bebis et al., 5358:846-55. Berlin: Springer. https://doi.org/10.1007/ 978-3-540-89639-5 81 .

Latour, Bruno. 1990. “Drawing Things Together.” In Representation in Scientific Practice, edited by Michael Lynch and Steve Woolgar, 19-68. Cambridge, MA: MIT Press.

Leonelli, Sabina. 2014. "What Difference Does Quantity Make? On the Epistemology of Big Data in Biology.” Big Data $\sigma^{\circ}$ Society 1 (1): 1-11. https://doi.org/10.1177/2053951714534395.

Mathewson, James H. 1999. "Visual-Spatial Thinking: An Aspect of Science Overlooked by Educators." Science Education 83 (1): 33-54. https://doi.org/

10.1002/(sici)1098-237x(199901)83:1.

Messaris, Paul. 1997. Visual Persuasion: The Role of Images in Advertising. Thousand Oaks, CA: SAGE Publications.

Miller, Helen B., and John K. Burton. 1994. "Images and Imagery Theory.” In Visual Literacy: A Spectrum of Visual Learning, edited by David M. Moore and Francis M. Dwyer, 65-83. Englewood Cliffs, NJ: Educational Technology Publishers.

Moser, Stephanie. 1996. "Visual Representation in Archaeology: Depicting the Missing-Link in Human Origins." In Picturing Knowledge: Historical छ Philosophical Problems Concerning the Use of Art in Science, edited by Brian S. Baigrie, 184-214. Toronto: University of Toronto Press. https://doi.org/10.3138/9781442678477-008.

Myers, Natasha. 2014. "Rendering Machinic Life.” In Representation in Scientific Practice Revisited, edited by Catelijne Coopmans, Janet Vertesi, Michael Lynch, and Steve Woolgar, 153-75. Cambridge, MA: MIT Press. https://doi.org/10.7551/mitpress/ 9780262525381.003.0008.

Myers, Natasha, and Joe Dumit. 2011. "Haptics." In A Companion to the Anthropology of the Body and Embodiment, Haptic Creativity and the Mid-Embodiments of Experimental Life, edited by Frances E. Mascia-Lees, 239-61. West Sussex, UK: Wiley-Blackwell. https://doi.org/10.1002/ 2781444340488.ch13. 
Peirce, Charles Sanders. 1998. "What Is a Sign? (1894).” In The Essential Peirce, Vol. 2, edited by The Peirce Edition Project, 4-10. Bloomington: Indiana University Press.

Rose, Deborah Bird. 2011. "Flying Fox: Kin, Keystone, Kontaminant." Australian Humanities Review 50 (May): 119-36. https://doi.org/10.22459/ahr.50.2011.07.

Scott, James C. 1998. Seeing like a State: How Certain Schemes to Improve the Human Condition Have Failed. New Haven, CT: Yale University Press.

Seels, Barbara A. 1994. "Visual Literacy: The Definition Problem.” In Visual Literacy: A Spectrum of Visual Learning, edited by David M. Moore and Francis M. Dwyer, 97-112. Englewood Cliffs, NJ: Educational Technology Publishers.

Tufte, Edward R. 2006. Beautiful Evidence. Cheshire, CT: Graphics Press.

UC Davis KeckCAVES. 2015. “Start [KeckCAVES].” 2015. https://keckcaves.org.

Vertesi, Janet. 2014. "Drawing as: Distinctions and Disambiguation in Digital Images of Mars.” In Representation in Scientific Practice Revisited, edited by Catelijne Coopmans, Janet Vertesi, Michael Lynch, and Steve Woolgar, 15-35. Cambridge, MA: MIT Press. https://doi.org/10.7551/mitpress/ $\underline{9780262525381.003 .0002 .}$.

Woelfle-Erskine, Cleo, and July Cole. 2015. "Transfiguring the Anthropocene: Stochastic Reimaginings of Human-Beaver Worlds.” TSQ: Transgender Studies Quarterly 2 (2): 297-316. https://doi.org/10.1215/23289252-2867625. 